\title{
ANALYSIS OF IMPACT OF RESIDENTIAL AIR CONDITIONERS ON DISTRIBUTION SYSTEMS
}

\author{
Sergio M. R. Sanhueza ${ }^{*}$, Fernando L. Tofoli** ${ }^{* *}$ José Carlos de Oliveira ${ }^{* * *}$, Geraldo C. Guimarães ${ }^{* * *}$ \\ * Escola Técnica Federal de Palmas, Coordenação Área Indústria \\ AE 310 Sul Av. NS 10 esq. c/ Av. LO-5A, Centro, CEP 77021-090, Palmas, TO \\ Email: sergiorivera@etfto.gov.br \\ **Centro Federal de Educação Tecnológica de Santa Catarina \\ Av. Nereu Ramos, 3450-D, Bairro Seminário, CEP 89813-000, Chapecó, SC \\ E-mail: fernandolessa@cefetsc.edu.br \\ ***Faculdade de Engenharia Elétrica, Universidade Federal de Uberlândia \\ Av. João Naves de Ávila, 2121, Bloco 3N - Campus Santa Mônica, 38402-900 Uberlândia, MG
}

\begin{abstract}
Air conditioners deserve special attention, because they represent a significant part of the power system load, mainly in high temperature regions. This work takes into account conventional air conditioners, and also variable-speed arrangements with and without undervoltage protection. The modeling of such type of load is analyzed for simulation purposes, as a novel representation of variable-speed units with undervoltage protection is introduced. The behavior of each air conditioner is verified in steady state operation considering typical power quality and voltage disturbances that occur in power systems such as voltage sags and interruptions. Furthermore, the influence of the aforementioned equipment on the power system is analyzed within the context of a distribution network.
\end{abstract}

Keywords - air conditioning, dynamic response, load modeling, power system dynamic stability.

\section{INTRODUCTION}

The impact of air conditioners on power systems has been intensively analyzed by engineers during many years for load modeling purposes and planning of utility distribution systems [1]. Such influence is not supposed to be neglected, once that they represent a significant part of the overall system load, mainly in high temperature regions.

Air conditioners can be classified as either conventional type or variable-speed type. Conventional air conditioners employ an asymmetrical two-phase motor with a starting capacitor. They operate with constant power independently of room temperature, because the compressor speed control is not present, being simply turned on/off by a thermostat. On the other hand, variable-speed air conditioners are supplied by frequency converters that automatically increase or decrease the compressor speed according to the preset temperature. When the room temperature increases, the speed and consequently the electric energy consumption also do. Otherwise when the temperature goes down, the speed decreases, reducing the power demand from the system.

In some cases, manufacturers offer an energy saving of $13 \%$ yearly for variable-speed air conditioners in comparison with conventional ones of same capacity. This is because

Manuscript received on 26/07/2007. Revised on 25/11/2007 and 02/10/2008. Accepted by recommendation of the Editor Fernando L. M. Antunes. normally the power electronic equipment is started with only $30 \%$ of the rated capacity. The speed adjustment occurs as a function of the room temperature, what is sometimes accomplished using fuzzy logic principles [2]. Power quality issues must also be considered when dealing with such equipment, such as in the prototype developed in [3], which presents low current harmonic distortion and high power factor.

The main focus of this paper is to present the modeling of both types of air conditioner in order to propose case studies and evaluate their dynamic response under power system disturbances. Furthermore two arrangements for variablespeed air conditioners are analyzed. The first model only accomplishes the common function of a PWM frequency converter, and the second one has undervoltage protection. The models described in this work are based on time domain, since the dynamic characteristics of mechanical and electrical parameters can be adequately represented, implying more reliable results for power quality studies [4]. In a second instance, the models are supposed to replace the typical representation involving impedance, current, and constant power.

\section{AIR CONDITIONER MODELING}

\section{A. Compressor Characteristics}

The compressor corresponds to the major component of any air conditioner because it compresses the freezing gas responsible for heat exchanges. For the driving motor, such load has different behavior during the startup and steady state operation.

In the starting condition, the torque-speed characteristic is quadratic with an initial torque around $30 \%$. However, when the compressor is running, the torque becomes constant with speed due to the compression of the freezing gas. Design engineers believe that the mechanical torque will remain relatively constant during the stall situation [5].

Since the compressor presents low inertia and constant torque during steady state operation, air conditioners tend to demand more power from the system during disturbances. This mechanism may explain some of the voltage collapse incidents reported in [6] and [7], and the delayed recovery of the transmission voltage following normally cleared multiphase faults as reported by Florida Power and Light Company [5] and Southern California Edison Company [8]. 


\section{B. Conventional Air Conditioners}

In a conventional air conditioner, the compressor is driven by an asymmetrical two-phase induction motor with a starting capacitor. The stator is composed by two windings, as shown in Figure 1. A main winding is responsible for the running condition, with positive sequence voltage. An auxiliary winding is used for startup, with negative sequence voltage. Capacitor $C$ has two functions, that are, to help the motor start and to correct power factor during steady state operation. Since the capacitor is designed for the motor operation at full speed, the starting torque is reduced.

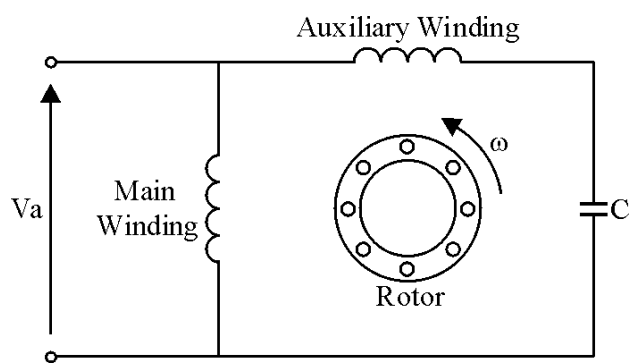

Fig. 1. Physical arrangement of the asymmetrical two-phase induction motor.

If the equivalent circuit in Figure 2 is considered, the motor model can be described by equations (1) to (4), which were presented in [9]. The model was evaluated and validated experimentally in [10].

$$
\begin{gathered}
{\left[\begin{array}{c}
v_{a} \\
v_{b} \\
0 \\
0
\end{array}\right]=\left[\begin{array}{cccc}
R_{a}+p L_{a a} & 0 & p M_{a B} & p M_{a B} \\
0 & R_{b}+p L_{b b} & p M_{b B} & p M_{b B} \\
p M_{A a} & p M_{A b} & R_{A}+p L_{A A} & 0 \\
p M_{B a} & p M_{B b} & 0 & R_{B}+p L_{B B}
\end{array}\right]\left[\begin{array}{c}
i_{a} \\
i_{b} \\
i_{A} \\
i_{B}
\end{array}\right]} \\
v_{c}=\frac{1}{C} \int i_{b} d t \\
T=T_{e}-J \frac{d \omega}{d t}-B \omega \\
+\left(\frac{P}{2}\right)\left[\frac{P}{2}\right)\left[\mathrm{L}_{a A} \sin \left(\frac{P}{2} \theta\right) i_{A}+\mathrm{L}_{a B} \cos \left(\frac{P}{2} \theta\right) i_{A}-\mathrm{L}_{b B} \sin \left(\frac{P}{2} \theta\right) i_{B}\right] i_{a}
\end{gathered}
$$

where:

$v_{a}, v_{b}, i_{a}, i_{b}$ - two-phase stator voltage and current;

$v_{A}, v_{B}, i_{A}, i_{B}$ - two-phase rotor voltage and current;

$v_{c}$ - capacitor voltage;

$C$ - starting capacitor;

$p$ - derivative operator $(d / d t)$;

$P$ - number of poles;

$R_{i}$ - stator resistance $(i=a, b)$;

$R_{j}$ - rotor resistance $(j=A, B)$;

$T$ - load torque;

$T_{e}$ - electromagnetic torque;

$L_{i i}$ - leakage inductance of winding $(i=a, b, A, B)$;

$M_{i j}$ - mutual inductance between stator $(i=a, b)$ and rotor $(j=A, B)$

$J$ - inertia moment;

$B-$ viscous friction coefficient;

$\omega$ - rotor angular speed; $\theta$ - angular displacement.

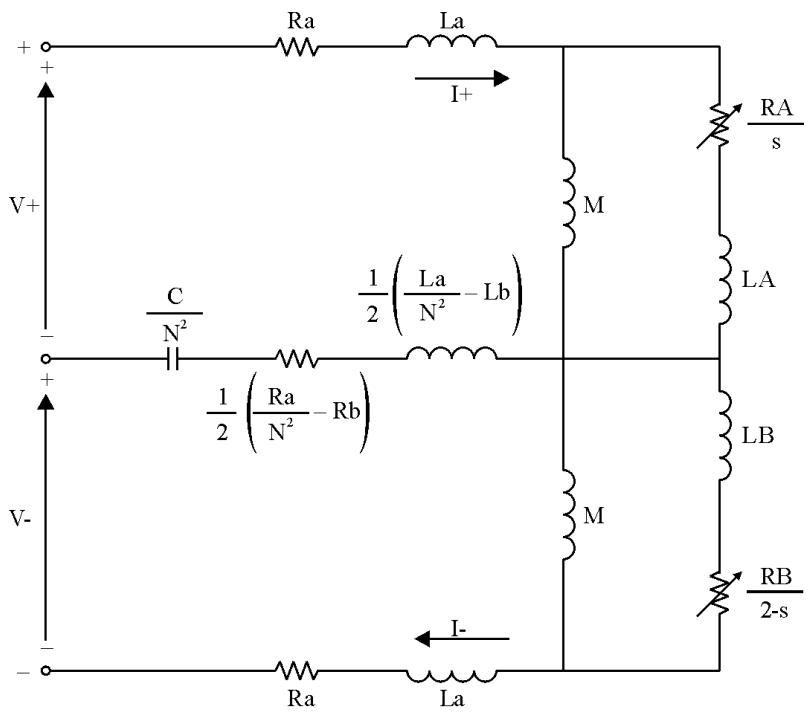

Fig. 2. Equivalent circuit of the asymmetrical two-phase induction motor.

\section{Variable-Speed Air Conditioners}

Variable-speed air conditioners correspond to an improvement of the previous model, where a three-phase induction motor is used instead, supplied by a frequency converter with single-phase input, as energy consumption can be controlled according to the room temperature. A typical schematic is shown in Figure 3.

It is believed that the employment of such equipment is supposed to increase significantly in the next few years since energy saving may become a priority for consumers. A research accomplished in 1999 reported that $86 \%$ of air conditioners in the Japanese power grid are of this type [11].

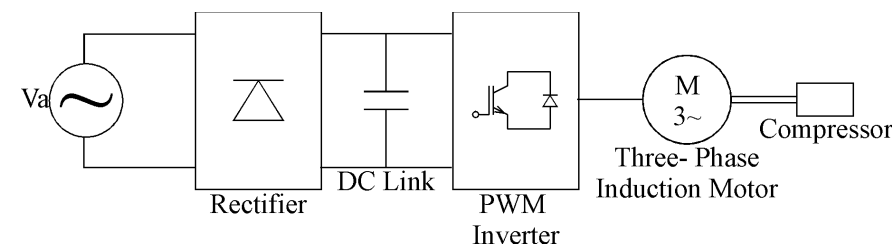

Fig. 3. Schematic representation of variable-speed air conditioners.

The equivalent circuit per phase of the three-phase induction motor is shown in Figure 4, where $R_{s}$ and $R_{r}$ are the stator and rotor resistances, and $L_{s}$ and $L_{r}$ are the stator and rotor leakage inductances, respectively. The magnetizing inductance is given by $M$ and $s$ corresponds to the rotor slip.

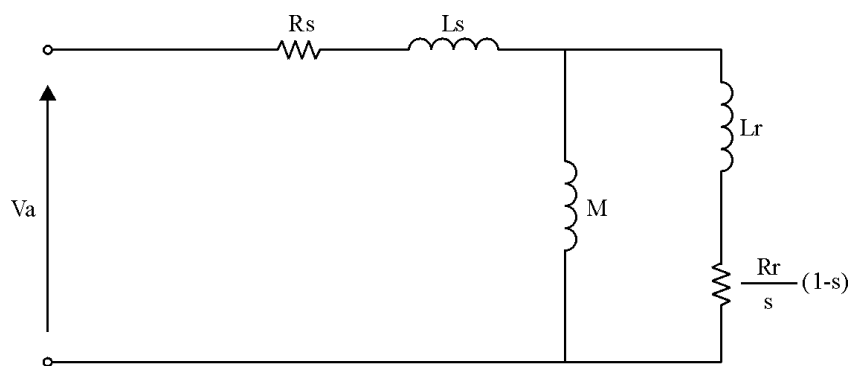

Fig. 4. Equivalent circuit per phase of the three-phase induction motor. 
According to [12], the model can be described by expressions (5) to (7), with the experimental validation presented in [13].

$$
\begin{gathered}
{[V]=[R][I]+[L] \frac{d[I]}{d t}+\frac{\partial[L]}{\partial \theta}[I] \frac{d \theta}{d t}} \\
T_{e}=\frac{P}{2} \sum_{i} \sum_{j} i_{i} j_{j} \frac{d L_{i j}}{d \theta} \\
T=T_{e}-J \frac{d \omega}{d t}-B \omega
\end{gathered}
$$

where:

$[L]$ - stator and rotor inductance matrix with $L_{i j}$ for $i, j=a$, $b, c, A, B, C$ $B, C$;

$[V]-$ vector representing the voltages of phases $a, b, c, A$, $B, C$;

$I]$ - vector representing the currents of phases $a, b, c, A$,

$[R]$ - stator and rotor resistance matrix with $R_{i j}=0$ and $R_{i i} \neq 0$, for $i, j=a, b, c, A, B, C$.

\section{Variable-Speed Air Conditioners with Undervoltage Protection}

This work analyzes two arrangements for the variablespeed air conditioner. The first one only accomplishes the common function of a frequency converter with PWM commutation. The second one was produced in Asia by Keling Electric [2], using a strategy that provides undervoltage protection.

The PWM technique is intensively used in inverters, and the switching instant is determined by the comparison between a sinusoidal signal and a triangle wave. When the sinusoidal reference is higher than the triangle carrier, the comparator output turns the semiconductor device on, otherwise it is turned off.

It is important to mention that the sinusoidal wave frequency determines the fundamental frequency of the voltage across the inverter mains. Therefore the inverter output frequency must vary in order to control the induction motor speed. However, the voltage must change so that the proper volts/hertz ratio is maintained constant, implying constant air gap flux and electromagnetic torque [14].

In low frequencies, the stator current increases causing a larger voltage drop across stator resistance $R_{s}$. Then the motor input voltage must reach a given boost voltage $V_{o}$. Taking this into account, inverters may have two voltage versus frequency characteristics i.e. linear offset or nonlinear, according to Figure 5. The linear characteristic can not be applied due to the boost voltage.

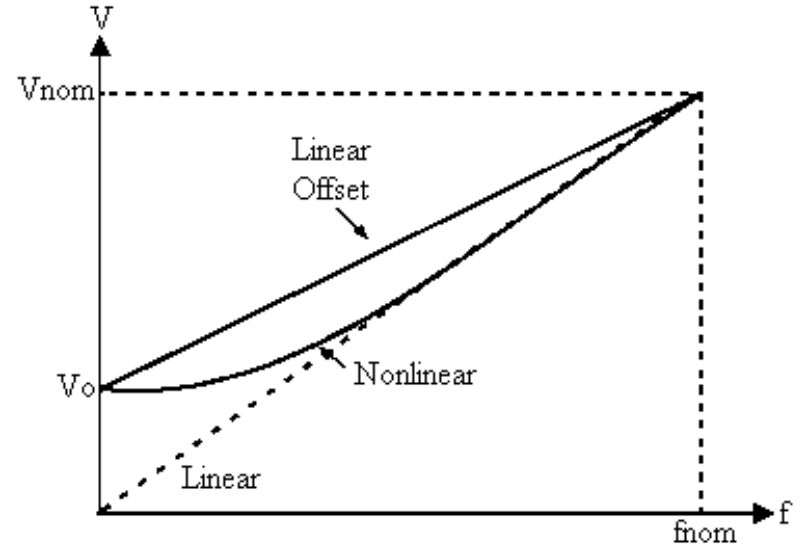

Fig. 5. Adjustment strategies for $V / f$ characteristics to keep the air gap flux constant.

Undervoltage protection consists in decreasing the operation frequency when the dc link voltage is reduced, keeping the volts/hertz ratio constant and preserving the electromagnetic torque in the induction motor. When the frequency decreases, there is a reduction in the motor speed, causing the mechanical power to be reduced as well. When the voltage level is reduced and the system is threatened by the voltage collapse phenomenon, reduction on the power demand of such equipment is a belief.

The modeling of air conditioners with undervoltage protection has not yet been developed and evaluated in studies that consider the power quality point of view. This is supposed to be the main contribution of this work and is discussed as follows.

\section{E. Modeling of Variable-Speed Air Conditioners with Undervoltage Protection}

When the disturbance occurs, the new operation frequency is obtained using the acceleration ramp represented in Figure 6 , as given by the following expression:

$$
V_{\text {nom }}=V_{o}+k f_{\text {nom }}
$$

where:

$V_{\text {nom }}$ - rated output voltage of the inverter [V];

$V_{o}-$ boost voltage [V];

$k$ - voltage gain per frequency unit $[\mathrm{V} / \mathrm{Hz}]$;

$f_{\text {nom }}$ - rated operation frequency $[\mathrm{Hz}]$.

The angular coefficient $k$ is given by:

$$
k=\frac{V_{\text {nom }}-V_{0}}{f_{\text {nom }}}
$$

If the voltage decreases to $V_{l}$, the frequency becomes $f_{l}$, and expression (9) is written as:

$$
k=\frac{V_{\text {nom }}-V_{1}}{f_{\text {nom }}-f_{1}}
$$




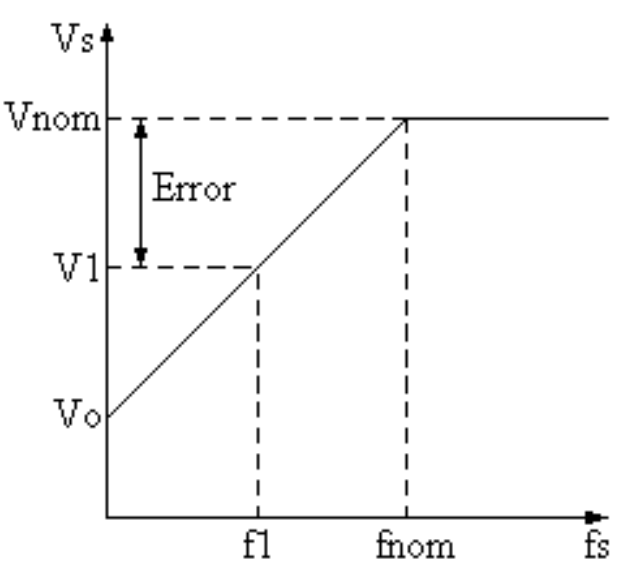

Fig. 6. Acceleration ramp.

From (10), the new operation frequency $f_{l}$ can be obtained as a function of $k$, which depends on the boost voltage according to (9), and also on the error between $V_{\text {nom }}$ and $V_{l}$.

$$
f_{1}=f_{\text {nom }}-\frac{\text { error }}{k}
$$

When the error is null, the operation frequency is $f_{\text {nom. }}$. Since the angular speed $\omega_{1}$ can be given as function of frequency $f_{l}$, the sinusoidal reference of the PWM control can be represented by (12).

$$
v_{r}=\sqrt{2} V_{r} \sin \left(\omega_{1} t\right)
$$

where:

$V_{r}$ - amplitude of the reference voltage [V];

$\omega_{1}-$ updated angular speed $[\mathrm{rad} / \mathrm{s}]$;

$t$ - time [s].

Considering that $v_{r}$ rotates anticlockwise around a horizontal reference axis with angular speed $\omega_{l}$ describing an angle $\phi$, expression (13) is obtained.

$$
\phi=\omega_{1} t
$$

Substituting (13) in (12) gives:

$$
v_{r}=\sqrt{2} V_{r} \sin \phi
$$

Since $\omega_{l}$ changes when there is a voltage variation, one can rewrite (13) as:

$$
d \phi=\omega_{1} d t
$$

Expression (15) can be rearranged as:

$$
\phi=\int \omega_{1} d t
$$

The aforementioned expressions can be used to implement the block diagram shown in Figure 7 , where $V_{d}$ and $V_{d}$ ' are the actual and desired voltages across the dc link, whose values are $\sqrt{2} V_{\text {nom }}$ and $\sqrt{2} V_{1}$, respectively.

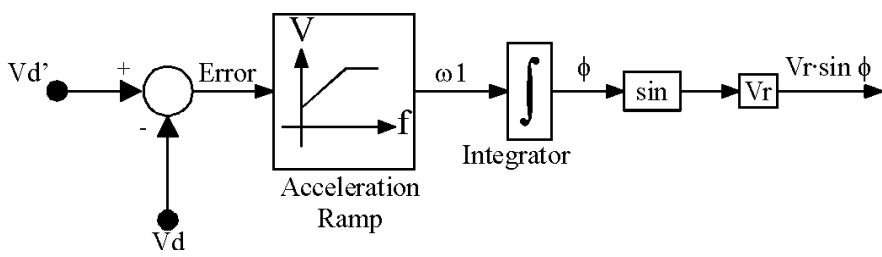

Fig. 7. Block diagram representing $V / f$ control.
The block diagram shown in Figure 7 does not include the actuation of PI or PID controllers since only the reduction of the compressor mechanical power is aimed, as proposed by the manufacturer. In such type of equipment, fuzzy logic is used to achieve speed control as a function of environment temperature. Some converters are able to maintain the proper $V / f$ ratio, as the control strategy becomes more complex, although they are not commonly employed in air conditioners [11]. However, it must be also mentioned that fuzzy logic may be useful in the parameters tuning of PI or PID controllers.

\section{ANALYSIS OF AIR CONDITIONING LOAD AS PART OF A DISTRIBUTION NETWORK}

The system shown in Figure 8 is composed by a $69-\mathrm{kV}$ transmission line connected to the substation at bus 4 , from where the distribution network supplied by transformer $T_{2}$ derives. The network contains four $50-\mathrm{kVA}$ transformers, whose loading is $50 \mathrm{kVA}$ at $0.9 \mathrm{lag}$. The load distribution is defined as in [15], where $25 \%$ is due to air conditioning, $5 \%$ is represented by refrigerators, and the rest is concerned with static loads related to lighting and heating. Evaluation tests are performed using Saber ${ }^{\circledR}$ software tool, where voltage and current waveforms are used in the calculation of powers based on the theory introduced by Budeanu [16].

For power system studies, utilities may consider the active power demand as $78 \%$ due to constant current-type loads and $22 \%$ due to constant impedance-type loads, and the whole reactive power demand is due to constant impedance-type loads. Furthermore, for a residential distribution network in a high temperature region where air conditioners are abundant, the transformer loading due to static loads is $70 \%$ [17].

To represent the power system under extreme situation, the transformers are assumed to operate at full load. Additionally, the transformer saturation effects and the core nonlinearity are considered in the analysis.

Based on the traditional equivalent circuit approach, and also considering the nonlinear characteristic of the ferromagnetic core of the transformer, one can represent the transformers as in Figure 9.

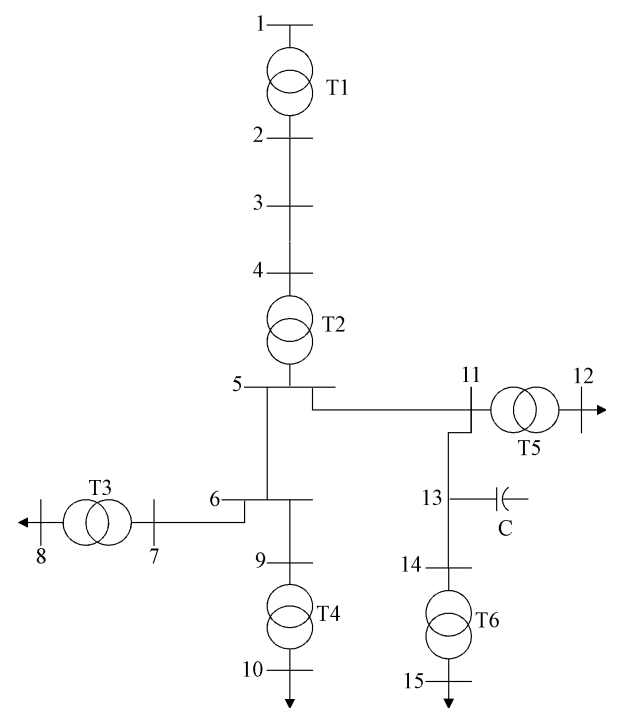

Fig. 8. Distribution power system. 


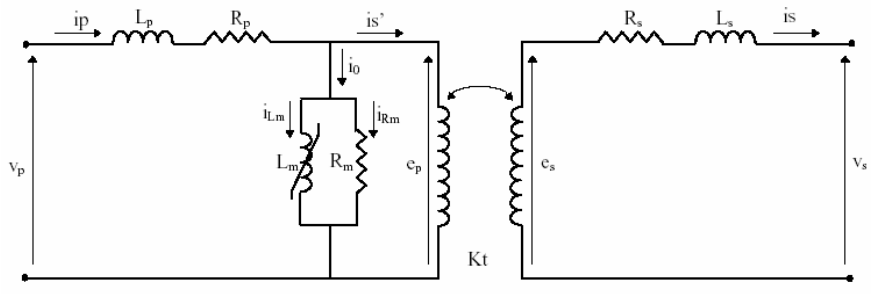

Fig. 9. Equivalent circuit of the distribution transformers.

where:

$v_{p}$ - phase-to-line voltage across the primary winding [V];

$v_{s}$ - phase-to-line voltage across the primary winding [V];

$e_{p}-$ induced counter-electromotive force across the primary winding [V];

$e_{s}-$ induced counter-electromotive force across the secondary winding $[\mathrm{V}]$;

$i_{s}$ - phase current through the secondary winding [A];

$i_{s}$ ' - phase current through the secondary winding referred to the primary side $[\mathrm{A}]$;

$i_{o}$ - magnetizing current $[\mathrm{A}]$;

$i_{R m}$ - portion of the current that corresponds to the core losses [A];

$i_{L m}-$ portion of the current that corresponds to the magnetic flux $[\mathrm{A}]$;

$i_{p}$ - phase current through the primary winding $[\mathrm{A}]$;

$R_{p}$ - resistance of the primary winding $[\Omega]$;

$R_{s}$ - resistance of the secondary winding $[\Omega]$;

$L_{p}$ - primary inductance $[\mathrm{H}]$;

$L_{s}$ - secondary inductance $[\mathrm{H}]$;

$R_{m}$ - magnetizing resistance, corresponding to the iron loss $[\Omega]$;

$L_{m}$ - magnetizing inductance [H];

$K_{t}-$ transformer turns ratio.

The magnetizing curve of the transformer, which is essential to represent the magnetic saturation, is shown in Figure 10.

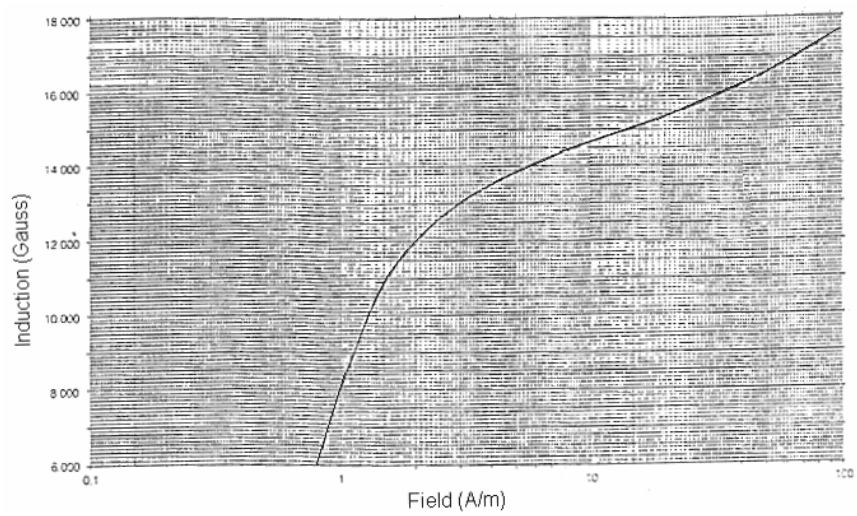

Fig. 10. Magnetizing curve of silicon steel manufactured by ACESITA.

Based on Figures 9 and 10, it is possible to determine the relationship between the primary and secondary voltages, magnetic flux, and the magnetizing inductance, according to expressions (17) to (21).

$$
v_{p}=R_{p} i_{p}+L_{p} \frac{d i_{p}}{d t}+e_{p}
$$

$$
\begin{gathered}
e_{s}=R_{s} i_{s}+L_{s} \frac{d i_{s}}{d t}+v_{s} \\
e_{p}=N_{p} \frac{d \phi}{d t} \\
e_{s}=N_{s} \frac{d \phi}{d t} \\
L_{m}=\frac{\phi}{i_{0}}
\end{gathered}
$$

where:

$\phi$ - magnetic flux [Wb];

$N_{p}$ - number of primary turns;

$N_{s}$ - number of secondary turns.

Once that the magnetic curve of the material presents distinct regions, several curve fitting techniques can be employed to represent it, such as polynomial adjustment, spline functions, linear interpolation, and similar methods. If linear interpolation is employed, the magnetizing curve can be obtained with satisfactory precision, due to the smooth characteristic of the curve.

Tables I to $\mathrm{V}$ represent the respective parameters of the transmission lines, transformers, and motors employed in the simulation.

Table I

Line Parameters

\begin{tabular}{cccc}
\hline Line Segment & $R(\Omega / \mathrm{km})$ & $X(\Omega / \mathrm{km})$ & $l(\mathrm{~km})$ \\
\hline $1-2$ & 0.2 & 0.5 & 20 \\
\hline $2-3$ & 0.2 & 0.5 & 20 \\
\hline $5-6$ & 0.19 & 0.38 & 4 \\
\hline $6-7$ & 0.19 & 0.38 & 2.5 \\
\hline $6-9$ & 0.19 & 0.38 & 2 \\
\hline $5-11$ & 0.19 & 0.38 & 0.5 \\
\hline $11-13$ & 0.19 & 0.38 & 0.5 \\
\hline $13-14$ & 0.19 & 0.38 &
\end{tabular}

Table II

Transformer parameters

\begin{tabular}{cccc}
\hline Transformer & $V(\mathrm{kV})$ & $S$ & $X(\%)$ \\
\hline$T_{1}$ & $13.8 / 69$ & $10 \mathrm{MVA}$ & 6 \\
\hline$T_{2}$ & $69 / 13.8$ & $10 \mathrm{MVA}$ & 6 \\
\hline$T_{3} \ldots T_{6}$ & $13.8 / 0.22$ & $50 \mathrm{kVA}$ & 3 \\
\hline
\end{tabular}

\section{Table III}

Parameters of the asymmetric two-phase induction motor used in a conventional air conditioner

\begin{tabular}{cccccccc}
\hline$R_{a}$ & $L_{a}$ & $R_{b}$ & $L_{b}$ & $R_{A}=R_{B}$ & $L_{A}=L_{B}$ & $J$ & $C$ \\
$(\Omega)$ & $(\mathrm{H})$ & $(\Omega)$ & $(\mathrm{H})$ & $(\Omega)$ & $(\mathrm{H})$ & $\left(\mathrm{kg} . \mathrm{m}^{2}\right)$ & $(\mu \mathrm{F})$ \\
\hline 0.48 & 0.10 & 1.43 & 0.06 & 5.62 & 0.04 & 0.0015 & 140 \\
\hline
\end{tabular}

Table IV

Parameters of the three-phase induction motor used in a variable-speed air conditioner

\begin{tabular}{cccccc}
\hline $\begin{array}{c}R_{s} \\
(\mathrm{pu})\end{array}$ & $\begin{array}{c}X_{s} \\
(\mathrm{pu})\end{array}$ & $\begin{array}{c}R_{r} \\
(\mathrm{pu})\end{array}$ & $\begin{array}{c}X_{r} \\
(\mathrm{pu})\end{array}$ & $\begin{array}{c}X_{M} \\
(\mathrm{pu})\end{array}$ & $\begin{array}{c}H \\
(\mathrm{~s})\end{array}$ \\
\hline 0.10 & 0.10 & 0.09 & 0.06 & 1.80 & 0.28 \\
\hline
\end{tabular}

Table V

Parameters of the three-phase induction motor used in a refrigerator

\begin{tabular}{cccccc}
\hline $\begin{array}{c}R_{s} \\
(\mathrm{pu})\end{array}$ & $\begin{array}{c}X_{s} \\
(\mathrm{pu})\end{array}$ & $\begin{array}{c}R_{r} \\
(\mathrm{pu})\end{array}$ & $\begin{array}{c}X_{r} \\
(\mathrm{pu})\end{array}$ & $\begin{array}{c}X_{M} \\
(\mathrm{pu})\end{array}$ & $\begin{array}{c}H \\
(\mathrm{~s})\end{array}$ \\
\hline 0.56 & 0.087 & 0.05 & 0.082 & 2.40 & 0.28 \\
\hline
\end{tabular}


where:

$X_{m}$ - magnetizing reactance;

$H$ - inertia constant.

\section{A. Fault Occurrence}

Considering that the air conditioning load is composed only by conventional units, the active power in steady state condition across the secondary side of transformer $T_{2}$ is 127 $\mathrm{kW}$, as shown in Figure 11. When the fault occurs, the active power is reduced to $100 \mathrm{~kW}$, since less active power is demanded due to the static load when voltage drops to 0.81 pu.

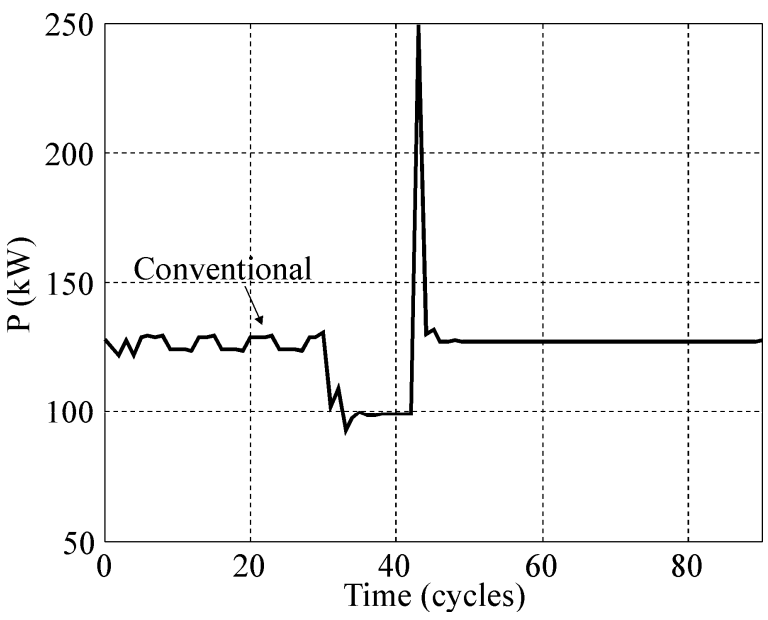

Fig. 11. Active power for conventional air conditioners.

Similar analysis can be performed as shown in Figure 12, by replacing conventional air conditioners with variablespeed equipment. If the normal-type arrangement is considered, the active power is reduced to $95 \mathrm{~kW}$. Otherwise, if adapted units represent the load, the reactive power demand is reduced to $64 \mathrm{~kW}$, which corresponds to the best performance during the fault.

For conventional air conditioners, the reactive power in steady state operation is $102 \mathrm{kVar}$, which decreases to 92 kvar for a short period during the fault. For the normal and adapted arrangements of variable-speed air conditioners, the reactive power decreases to $70 \mathrm{kVar}$ and $50 \mathrm{kVar}$, respectively.

In the aforementioned situations, there is a sudden increase in the active power at the end of the disturbance due to the compressor rotation speed, which is reduced when the fault occurs.

It is possible to notice in Figures 11 and 12 that the active power peak is greater for the variable-speed equipment. On the other hand, Figures 13 and 14 show that the reactive power peak is greater in the conventional air conditioners. This is due to the current that charges the dc-link capacitor after the sag occurrence, according to Figure 15. This behavior has also been analyzed in [12] and [17].

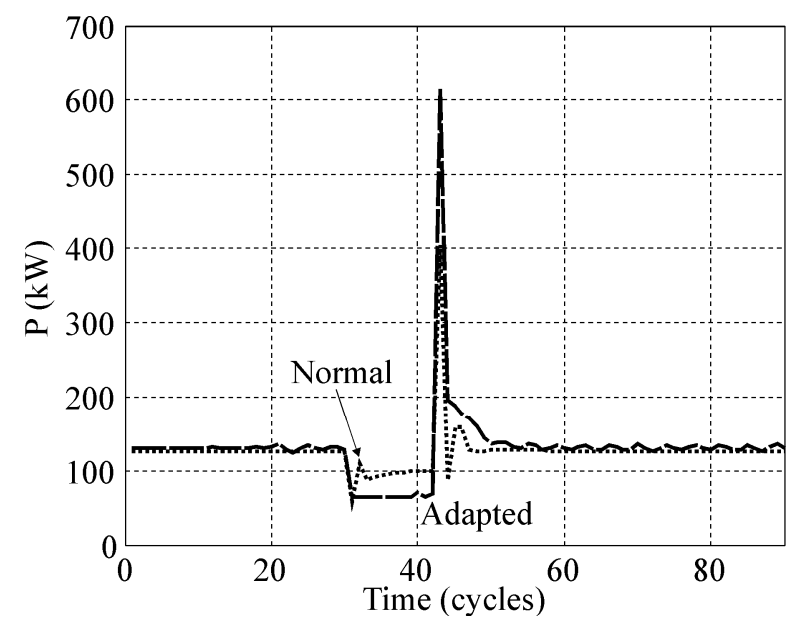

Fig. 12. Active power for variable-speed air conditioners.

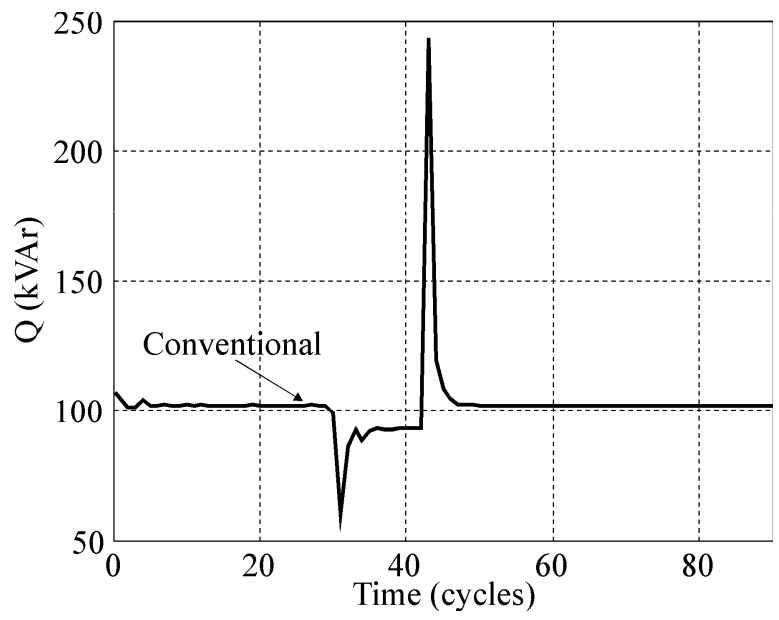

Fig. 13. Reactive power for conventional air conditioners.

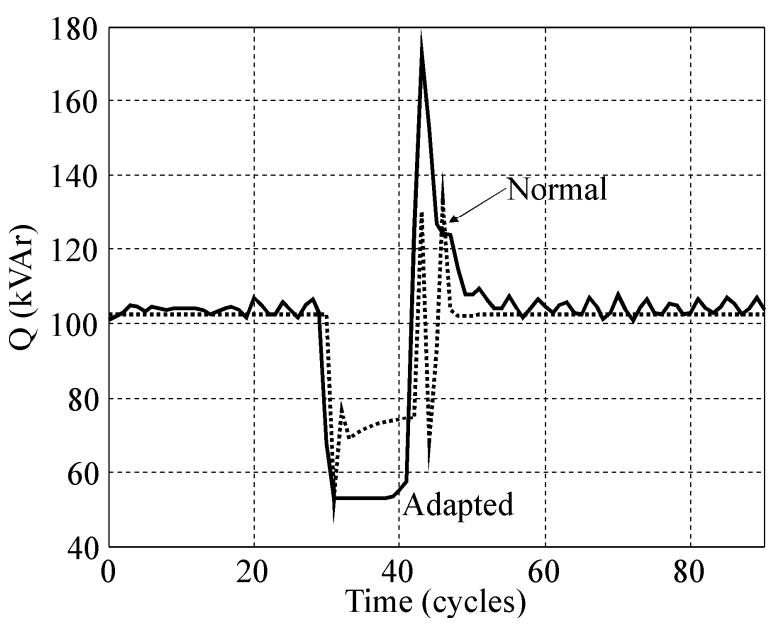

Fig. 14. Reactive power for variable-speed air conditioners. 


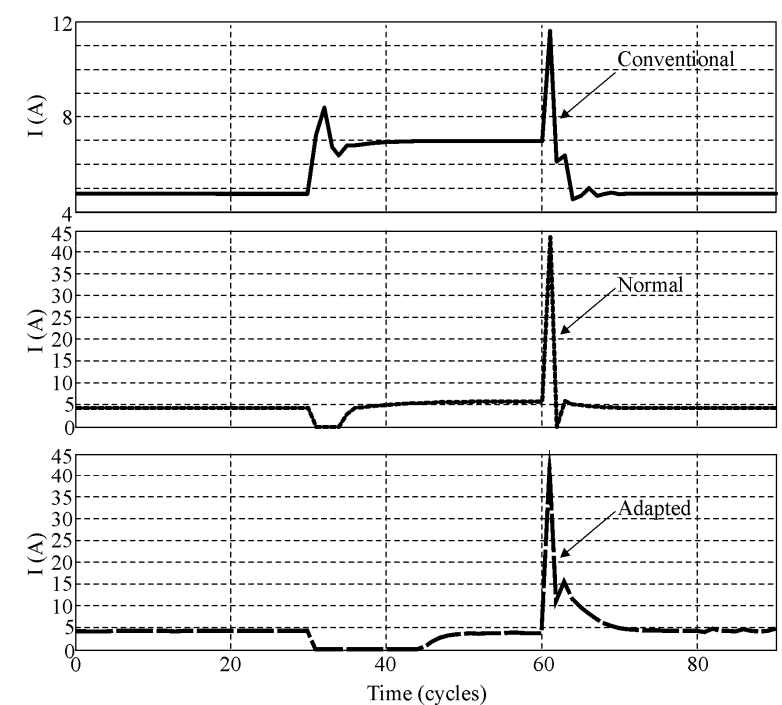

Fig. 15. Behavior of the current through the air conditioners during the voltage sag.

\section{CONCLUSION}

Variable-speed air conditioners can be very attractive because temperature control is a desirable characteristic that makes the rational use of energy possible. The starting operation does not need to occur at full load, and there is also the adjustment of the necessary power in agreement with the environment temperature. However, such equipment presents higher cost when compared to the conventional-type air conditioner.

Another advantage over the conventional configuration is the behavior during voltage sags. The variable-speed air conditioner absorbs high amount of active and reactive power, while the conventional one maintains the power flow stable until the utility voltage is normalized. However, high amount of active power is necessary to recharge the capacitor. Variable-speed air conditioners use a frequency converter with sinusoidal pulse width modulation, as two arrangements are possible. The first configuration does not present undervoltage protection, and has been thoroughly studied in previous works. The second one accomplishes this function by adjusting the volts/hertz ratio for the motor, monitoring the dc link voltage to control the operation frequency and keep the developed torque constant.

The adapted arrangement has the advantage of minimizing the power transferred to the load when the dc link voltage is reduced. An air conditioner that employs this technique absorbs a larger amount of active and reactive power from the system when the voltage level is restored, as this situation is analogous to the motor startup. However, its application is still recommended because when the system voltage is low, the power demand is also lower than in normal condition.

The analysis of a distribution network with transformers at full load has shown that variable-speed units demand less active power when the utility voltage is reduced (for instance, due to fault occurrence), which may be desirable for generators under this condition.

\section{ACKNOWLEDGEMENT}

The authors would like to acknowledge CAPES for the financial support to this work.

\section{REFERENCES}

[1] D. Bargiotas, J.D. Birdwell, "Residential Air Conditioner Dynamic Model For Direct Load Control", IEEE Transactions on Power Delivery, vol. 3, no. 4, pp. 2119-2126, October 1988.

[2] S.G. Sheng, A. Sai, S. Tugio, "Advanced and Economical Household Inverter Air Conditioner Controller Solution", in Proc. of the International IC'99, pp. 83-92, 1999.

[3] C.A. Canesin, F.A.S. Gonçalves, E. Leandro, J.O.P. Pinto "Variable Speed Refrigeration with HPF Voltage Source Rectifier", in Proc. 9th Brasilian Power Electronics Conference, September 30th-October 4th, 2007, Blumenau-SC.

[4] K. Tomiyama, J.P. Daniel., S. Ihara, "Modeling Air Conditioner Load for Power System Studies", IEEE Transactions on Power Systems, vol. 13, no. 2, pp. 414421, May 1998.

[5] J.W. Shaffer, "Air Conditioner Response to Transmission Faults", IEEE Transactions on Power Systems, vol. 12, no. 2, pp. 614-621, May 1997.

[6] A. Kurita, T. Sakura, "The Power System Failure on July 23, 1987 in Tokyo", in Proc. of the 27th Conference on Decision and Control, Austin, Texas, December 1988, pp. 2093-2097.

[7] Y. Hain, I. Schwitzer, "Analyses of the Power Blackout of June 8, 1995 in the Israel Electric Corporation", IEEE Transactions on Power Systems, vol. 12, no. 4, pp. 17521758, November 1997.

[8] B.R. Williams, W.R. Schmus "Transmission Voltage Recovery Delayed by Stalled Air Conditioner Compressors", IEEE Transactions on Power Systems, vol. 7, no. 3, pp. 1173-1181, August 1992.

[9] P.C. Krause "Simulation of Unsymmetrical 2-Phase Induction Machines", IEEE Transactions on Power Apparatus and Systems, vol. 84, no. 11, pp. 1025-1037, 1965.

[10] S.M.R. Sanhueza, G.C. Guimarães, J.C. Oliveira, C.A.G. Medeiros, B.C. Carvalho, F.L. Tofoli, F.L. Albuquerque, "Impact of Simultaneous Operation of Air Conditioners on Power Systems", in Proc. 5th Latin-American Congress: Electricity Generation and Transmission, São Pedro, São Paulo, Brazil.

[11]J. Donlon, J. Achhammer, H. Iwamoto, M. Iwasaki, "Power Modules for Appliance Motor Control", IEEE Industry Applications Magazine, vol. 8, no. 4, pp 26-34, July/August 2002.

[12]P.C.A. Leão, J.C. Oliveira "A Computational and Practical Analysis of VSI-PWM Frequency Converter Under Balanced and Unbalanced Voltage Sag", in Proc. 10th International Conference on Harmonics and Quality of Power, 2002, vol. 2, pp. 730-736.

[13]L. Martins Neto, C.H. Salerno, B.P. Alvarenga, "Harmonic Inductance in The Linear Analysis of 
Induction Motor", in Proc. International Conference on Electrical Machines in Australia, Australia, Adelaide, September 1993.

[14] J.M.D. Murphy, F.G. Turnbull, Power Electronic Control of AC Motors, 1st ed., Oxford, Pergamon Press, 1988.

[15] IEEE Task Force on Load Representation for Dynamic Performance, "Load Representation for Dynamic Performance Analysis", IEEE Transactions on Power Systems, vol. 8, no. 2, May 1993, pp. 472-482.

[16] C.I. Budeanu, "Reactive and Fictitious Powers", in Publ. no. 2 of the Rumanian National Institute of Energy, Bucharest, Romania, 1927.

[17] S.M.R. Sanhueza "Modelagem e Análise de Condicionadores de Ar dos Tipos Convencional e Inteligente e Influência no Comportamento de Redes Elétricas de Distribuição", Tese de Doutorado, Uberlândia, 2007.

\section{BIOGRAPHIES}

Sergio M. R. Sanhueza was born in Santiago, Chile, in 1975. He received the B.Sc. degree in electrical engineering from the Federal University of Mato Grosso do Sul, Campo Grande, Brazil. He also received the M.Sc. and Ph.D. degrees in electrical engineering in 2002 and 2006, respectively, from the Federal University of Uberlândia, Uberlândia, Brazil.

Currently, he is a Professor with the Federal Technical School of Palmas, Palmas, Brazil. His research interest areas are electric power systems, load modeling, power quality, and renewable energy.

Fernando L. Tofoli was born on March 11, 1976, in São Paulo, Brazil. He received the B.Sc., M.Sc., and Ph.D. degrees in electrical engineering from the Federal University of Uberlândia, Uberlândia, Brazil, in 1999, 2002, and 2005, respectively.

Currently, he is a Professor with the Center of Federal Technological Education of Santa Catarina, Chapecó, Brazil. His research interests include power-quality-related issues, high-power factor rectifiers, and soft switching techniques applied to static power converters.

José Carlos de Oliveira was born in Itajubá, Brazil. He received the B.Sc. and M.Sc. degrees from Federal University of Itajubá, Brazil, and $\mathrm{PhD}$ degree from the University of Manchester, Institute of Science Technology, Manchester, United Kingdom, respectively.

Currently, he is a Professor with the Federal University of Uberlândia, Uberlândia, Brazil. He has taught and published in a variety of subjects, related to electrical power systems and power quality.

Geraldo C. Guimarães was born in Patos de Minas, Brazil, in 1954. He received the B.Sc. degree in electrical engineering from the Federal University of Uberlândia, Uberlândia, Brazil in 1977. He received the M.Sc. degree from the Federal University of Santa Catarina, Brazil in 1984, and the PhD degree from the University of Aberdeen, Scotland, in 1990.

Currently, he is a Professor with the Federal University of Uberlândia, Uberlândia, Brazil. His research interest areas are power system dynamics, distributed generation, renewable energy, and applied electromagnetism. 